\title{
PARTISIPASI PETANI DALAM KEGIATAN KELOMPOKTANI (Studi Kasus pada Kelompoktani Irmas Jaya di Desa Karyamukti Kecamatan Pataruman Kota Banjar)
}

\author{
Oleh: \\ Aip Rusdiana ${ }^{1}$, Dedi Herdiansah $\mathrm{S}^{2}$, Tito Hardiyanto \\ ${ }^{1,2,3}$ Fakultas Pertanian Universitas Galuh
}

\begin{abstract}
ABSTRAK
Penelitian ini bertujuan untuk mengetahui 1) karateristik sosial ekonomi petani peserta kegiatan SLPTT padi sawah, 2) tingkat partisipasi petani dalam kegiatan kelompoktani. Metode yang digunakan dalam penelitian ini adalah metode studi kasus dengan mengambil kasus pada pada Kelompoktani Irmas Jaya di Desa Karyamukti Kecamatan Pataruman Kota Banjar. Sampel yang diambil dalam penelitian ini adalah anggota Kelompoktani Irmas Jaya sebanyak 30 orang petani atau 25 persen dari 120 petani yang telah mengikuti kegiatan SL-PTT padi sawah. Dari hasil penelitian diperoleh 1) tingkat karakteristik sosial ekonomi petani peserta kegiatan SL-PTT padi sawah di Kelompoktani Irmas Jaya sebagian besar berada pada kategori sedang sebanyak 25 orang atau 83,33 persen, terbesar kedua berada pada kategori tinggi sebanyak 3 orang atau 10,00 persen dan yang terakhir berada pada kategori rendah sebanyak 2 orang atau 6,67 persen, 2) tingkat partisipasi petani dalam kegiatan kelompoktani adalah tinggi dengan berada di tangga Partnership level Citizen Power, yaitu dapat diartikan bahwa petani yang hadir dalam pertemuan tersebut dapat bernegosiasi dan terlibat dalam pengambilan keputusan.
\end{abstract}

\section{Kata Kunci : Kelompoktani, Partisipasi petani, Karakteristik Sosial Ekonomi Petani}

\section{PENDAHULUAN}

Keberhasilan pembangunan pertanian tidak bisa terlepas dari partisipasi masyarakat tani. Pembangunan yang dilaksanakan pemerintah tentunya bertujuan untuk mencapai masyarakat yang sejahtera sehingga posisi masyarakat merupakan posisi yang penting dalam proses pelaksanaan pembangunan yang dilaksanakan oleh pemerintah. Pembangunan akan dinilai berhasil jika pembangunan tersebut membawa sebuah perubahan kesejahteraan dalam masyarakat sehingga proses pembangunan merupakan proses tawar-menawar antara kebutuhan masyarakat dan keinginan pemerintah. Oleh karena itu dalam pelaksanaan pembangunan, partisipasi masyarakat merupakan hal yang sangat mempengaruhi keberhasilan proses pembangunan itu sendiri (Iwan, 2010).

Partisipasi petani dalam mengikuti kegiatan di kelompoktani dipengaruhi oleh banyak faktor. Beberapa faktor yang berhubungan dengan tingkat partisipasi diantaranya adalah faktorfaktor yang berasal dari masyarakat itu sendiri, misal dari karakteristik sosial ekonomi petani sendiri (Hasyim, 2006).

Terlepas dari berbagai persoalan, banyak pihak menyadari bahwa kegiatan penyuluhan pertanian masih sangat diperlukan oleh petani. Kondisi pertanian rakyat masih lemah dalam banyak aspek, sementara tantangan yang dihadapi semakin berat, jadi sebenarnya mereka justru memerlukan kegiatan penyuluhan yang makin intensif, berkesinambungan dan terarah. Untuk mewujudkan kondisi penyuluhan pertanian seperti ini memang tidak mudah dan tidak mungkin dapat dilakukan dalam waktu singkat. Meskipun demikian upaya-upaya perbaikan yang nyata perlu segera dilakukan, karena jika tidak kinerja penyuluhan pertanian yang memang sudah mengalami kemunduran besar akan semakin memburuk.

Salah satu metode penyuluhan yang berfungsi untuk memecahkan permasalahan yang terjadi di desa dengan objek metode adalah Metode Sekolah Lapang Pengelolaan Tanaman Terpadu (SL-PTT) yang dicanangkan Pemerintah guna meningkatkan kualitas dan produktivitas padi. Metode ini sangat membantu para petani padi dalam melakukan pengelolaan untuk hasil yang lebih baik (Mar, 2010).

Melalui penerapan kegiatan SL-PTT pada tingkat kelompoktani maka diharapkan petani akan mampu mengelola sumberdaya yang tersedia (tanah, air dan sarana produksi) secara terpadu dalam melakukan budidaya di lahan usahataninya berdasarkan kondisi spesifik lokasi sehingga petani menjadi lebih terampil serta mampu mengembangkan usahataninya dalam 
rangka peningkatan produksi padi (Dinas Pertanian dan Ketahanan Pangan Kota Banjar, 2013).

\section{METODE PENELITIAN \\ Jenis Penelitian}

Jenis penelitian yang digunakan adalah metode study kasus, dengan mengambil kasus pada Kelompoktani Irmas Jaya Desa Karyamukti Kecamatan Pataruman Kota Banjar. Menurut Daniel (2003), studi kasus merupakan suatu penelitian yang bersifat mendalam, terarah, terfokus pada sifat tertentu mengenai suatu objek tertentu. mengenai suatu karakteristik tertentu dari objek penelitian.

\section{Teknik Pengumpulan Data}

Metode pengumpulan data adalah observasi langsung, dengan menggunakan daftar pertanyaan yang telah dipersiapkan terlebih dahulu. Data yang dikumpulkan dalam penelitian ini terdiri dari data primer dan data sekunder. Data primer diperoleh dari keterangan petani anggota kelompok tani selaku responden. Sedangkan data sekunder diperoleh dari lembaga atau instansi terkait dan beberapa buku-buku pendukung penelitian.

Metode sampel yang digunakan adalah metode acak sederhana (Simple Random Sampling). Sampel yang diambil dalam penelitian ini adalah anggota Kelompoktani Irmas Jaya sebanyak 30 orang petani atau 25 persen dari 120 petani yang telah mengikuti kegiatan SL-PTT padi sawah. Menuut Daniel (2003) bahwa metode acak sederhana adalah suatu cara pengambilan sampel sedemikian rupa hingga semua anggota populasi mempunyai kesempatan yang sama untuk dipilih menjadi sampel.

\section{Rancangan Analisis Data}

Untuk identifikasi masalah 1, dianalisis dengan menggunakan analisis deskriptif yaitu dengan menggunakan kuesioner yang dijawab oleh petani sampel. Tingkat karakteristik sosial ekonomi petani peserta kegiatan SL-PTT padi sawah dibagi ke dalam tiga kategori dengan panjang interval untuk setiap kategori dihitung dengan rumus (Sudjana, 2000).

$$
\begin{aligned}
& \text { Panjang Kelas Interval } \\
& =\frac{\text { Rentang }}{\text { Banyak Kelas }} \\
& \text { Nilai Maksimal - Nilai Minimal } \\
& =\frac{18-6}{3} \\
& \text { Jumlah Kategori } \\
& =4
\end{aligned}
$$

Dari perhitungan tersebut maka dapat diketahui kategori karakteristik petani peserta SL-PTT padi sawah yaitu :

1. Tingkat Karakteristik Petani Rendah $(6 \leq \mathrm{Q}<$ 10)

2. Tingkat Karakteristik Petani Sedang $(10 \leq \mathrm{Q}$ $<14$ )

3. Tingkat Karakteristik Petani Tinggi $(14 \leq \mathrm{Q}$ $\leq 18)$

Keterangan : Q adalah nilai yang dicapai.

Untuk identifikasi masalah 2, dianalisis dengan menggunakan analisis deskriftif 8 tangga tingkatan partisipasi. Tingkat partisipasi kelompoktani diukur dari Frekuensi kehadiran dalam pertemuan, Keaktifan kelompok dalam berdiskusi, Keterlibatan dalam kegiatan fisik dan Kesediaan membayar iuran atau sumbangan.

\section{HASIL DAN PEMBAHASAN}

\section{Karakteristik Sosial Ekonomi Petani Peserta SL-PTT Padi Sawah}

Karateristik sosial ekonomi petani yang mengikuti kegiatan Sekolah Lapang Pengelolaan Tanaman Terpadu (SL-PTT) padi sawah, meliputi tingkat pendidikan, umur, pengalaman bertani, jumlah tanggungan, luas lahan dan frekuensi mengikuti penyuluhan.

\section{Tingkat Pendidikan}

Tingkat pendidikan formal yang dicapai oleh petani sampel pada kegiatan SL-PTT padi sawah dapat dilihat pada Tabel 1 berikut ini.

Tabel 1. Karakteristik Sosial Ekonomi Berdasarkan Tingkat Pendidikan

\begin{tabular}{|c|l|c|c|}
\hline \multirow{2}{*}{ No } & \multirow{2}{*}{ Tingkat Pendidikan } & \multicolumn{2}{|c|}{ Jumlah } \\
\cline { 3 - 4 } & & Orang & Persentase $(\%)$ \\
\hline 1. & Tidak Tamat SD/Tamat SD & 21 & 70,00 \\
\hline 2. & Tamat SMP & 8 & 26,67 \\
\hline 3. & Tamat SMA/Perguruan tinggi & 1 & 3,33 \\
\hline \multicolumn{2}{r}{ Jumlah } & $\mathbf{3 0}$ & $\mathbf{1 0 0 , 0 0}$ \\
\hline
\end{tabular}


Berdasarkan Tabel 1 dapat dilihat bahwa tingkat pendidikan formal responden sangatlah bervariasi, dimana sebagian besar adalah tidak tamat atau tamat SD sebanyak 21 orang atau 70 persen, sedangkan yang tamat SMP sebanyak 8 orang atau 26,67 persen dan tamat SMA atau perguruan tinggi 1 orang atau 3,33 persen.

\section{Umur}

Untuk mengetahui karakteristik sosial ekonomi petani berdasarkan umur di Kelompoktani Irmas Jaya Desa Karyamukti dapat dilihat pada Tabel 2.

Tabel 2. Karakteristik Sosial Ekonomi Berdasarkan Kelompok Umur

\begin{tabular}{|c|c|c|c|}
\hline \multirow{2}{*}{ No } & \multirow{2}{*}{$\begin{array}{c}\text { Kelompok Umur } \\
\text { (tahun) }\end{array}$} & Orang & Persentase (\%) \\
\cline { 3 - 4 } & $\leq 14$ & 0 & 0,00 \\
\hline 1. & $15-64$ & 29 & 96,67 \\
\hline 2. & $\geq 65$ & 1 & 3,33 \\
\hline 3. & Jumlah & $\mathbf{3 0}$ & $\mathbf{1 0 0 , 0 0}$ \\
\hline & &
\end{tabular}

Berdasarkan data pada Tabel 2 dapat diketahui bahwa sebagian besar responden di Kelompoktani Irmas Jaya berumur 15 sampai 64 tahun sebanyak 29 orang atau 96,67 persen, hal ini sejalan dengan pendapat Nurdin (2000) yang menyatakan bahwa penduduk usia produktif adalah penduduk yang berusia 15 sampai 64 tahun.

\section{Pengalaman Bertani}

Karakteristik sosial ekonomi petani berdasarkan pengalaman bertani di Kelompoktani Irmas Jaya Desa Karyamukti dapat dilihat pada Tabel 3.

Tabel 3. Karakteristik Sosial Ekonomi Berdasarkan Pengalaman Bertani

\begin{tabular}{|c|c|c|c|}
\hline \multirow{2}{*}{ No } & $\begin{array}{c}\text { Pengalaman Bertani } \\
\text { (tahun) }\end{array}$ & Orang & Persentase (\%) \\
\cline { 3 - 4 } & $\leq 10$ & 7 & 23,33 \\
\hline 1. & $11-20$ & 10 & 33,33 \\
\hline 2. & $>20$ & 13 & 43,33 \\
\hline 3. & Jumlah & $\mathbf{3 0}$ & $\mathbf{1 0 0 , 0 0}$ \\
\hline
\end{tabular}

Berdasarkan Tabel 3 dapat diketahui bahwa pengalaman bertani responden sebagian besar di atas 10 tahun sebanyak 23 orang atau 76,66 persen dan sisanya 7 orang atau 23,33 persen dengan memiliki pengalaman kurang dari 11 tahun.

\section{Jumlah Tanggungan}

Jumlah tanggungan responden dapat dilihat pada tabel 4 berikut ini.

Tabel 4. Karakteristik Sosial Ekonomi Berdasarkan Tanggungan Keluarga

\begin{tabular}{|c|c|c|c|}
\hline \multirow{2}{*}{ No } & Tanggungan Keluarga & \multicolumn{2}{|c|}{ Jumlah } \\
\cline { 3 - 4 } & (orang) & Orang & Persentase (\%) \\
\hline 1. & $1-2$ & 10 & 33,33 \\
\hline 2. & $3-4$ & 20 & 66,67 \\
\hline 3. & $>4$ & 0 & 0,00 \\
\hline & Jumlah & $\mathbf{3 0}$ & $\mathbf{1 0 0 , 0 0}$ \\
\hline
\end{tabular}

Tabel 4 menunjukkan bahwa sebagian besar responden memliki jumlah tanggungan 3 sampai 4 orang sebanyak 20 orang atau 66,67 persen dan sebanyak 10 orang atau 33,33 persen memiliki jumlah tanggungan 1 sampai 2 orang. 


\section{Luas Lahan}

Luas lahan responden yang digunakan untuk usahatani padi sawah dapat dilihat pada Tabel 5 berikut ini.

Tabel 5. Karakteristik Sosial Ekonomi Berdasarkan Luas Lahan

\begin{tabular}{|c|c|c|c|}
\hline \multirow{2}{*}{ No } & \multirow{2}{*}{$\begin{array}{c}\text { Luas Lahan } \\
(\mathrm{Ha})\end{array}$} & Orang & Persentase (\%) \\
\cline { 3 - 4 } & $<0,25$ & 19 & 63,33 \\
\hline 1. & $0,25-0,5$ & 8 & 26,67 \\
\hline 2. & $>0,5$ & 3 & 10,00 \\
\hline 3. & Jumlah & $\mathbf{3 0}$ & $\mathbf{1 0 0 , 0 0}$ \\
\hline
\end{tabular}

Berdasarkan Tabel 5 dapat diketahui sebagian besar responden memiliki luas lahan kurang dari 0,50 hektar yaitu sebanyak 27 orang atau 90,00 persen, sedangkan yang memiliki luas lahan lebih dari 0,50 hektar sebanyak 3 orang atau 10 persen dari seluruh responden.

\section{Frekuensi Penyuluhan}

Frekuensi petani dalam mengikuti penyuluhan dapat dilihat pada Tabel 6.

Tabel 6. Karakteristik Sosial Ekonomi Berdasarkan Frekuensi Mengikuti Penyuluhan

\begin{tabular}{|c|c|c|c|}
\hline \multirow{2}{*}{ No } & FrekuensiMengikuti & \multicolumn{2}{|c|}{ Jumlah } \\
\cline { 3 - 4 } & Penyuluhan (kali) & Orang & Persentase (\%) \\
\hline 1. & $1-2$ & 0 & 0,00 \\
\hline 2. & $3-5$ & 8 & 26,67 \\
\hline 3. & $6-8$ & 22 & 73,34 \\
\hline & Jumlah & $\mathbf{3 0}$ & $\mathbf{1 0 0 , 0 0}$ \\
\hline
\end{tabular}

Berdasarkan Tabel 6 dapat diketahui bahwa sebagian besar responden mengikuti kegiatan penyuluhan 6 sampai 8 kali sebanyak 22 orang atau 73,34 persen, sedangkan responden yang mengikuti kegiatan penyuluhan 3 sampai 5 kali sebanyak 8 orang atau 26,67 persen dari seluruh responden.

\section{Tingkat Karakteristik Sosial Ekonomi}

Tingkat karakteristik sosial ekonomi petani peserta kegiatan SL-PTT padi sawah di Kelompoktani Irmas Jaya dapat dilihat pada Tabel 7 berikut ini.

Tabel 7. Tingkat Karakteristik Sosial Ekonomi Petani Peserta Kegiatan SL-PTT Padi Sawah

\begin{tabular}{|c|c|c|c|}
\hline No & Kategori & $\begin{array}{c}\text { Jumlah Petani } \\
\text { (Orang) }\end{array}$ & $\begin{array}{c}\text { Persentase } \\
(\%)\end{array}$ \\
\hline 1. & Rendah & 2 & 6,67 \\
\hline 2. & Sedang & 25 & 83,33 \\
\hline 3. & Tinggi & 3 & 10,00 \\
\hline & Jumlah & $\mathbf{3 0}$ & $\mathbf{1 0 0 , 0 0}$ \\
\hline
\end{tabular}

Dari Tabel 7 dapat diketahui bahwa karakteristik petani peserta kegiatan SL-PTT padi sawah sebagian besar berada pada kategori sedang sebanyak 25 orang atau 83,33 persen, kedua terbesar berada pada kategori tinggi sebanyak 3 orang atau 10,00 persen dan yang terakhir berada pada kategori rendah sebanyak 2 orang atau 6,67 persen.

\section{Tingkat Partisipasi Petani Dalam Kegiatan Kegiatan Kelompoktani}

Konsep partisipasi yang digunakan dalam penelitian ini adalah konsep partisipasi Sherry Arstein (1969) yang lebih dikenal dengan istilah "Delapan Tangga Partisipasi Arnstein". Konsep ini membagi tingkat partisipasi kedalam delapan tingkatan partisipasi yang digolongkan kedalam tiga golongan besar. Pertama adalah derajat terbawah, yaitu non participation (manipulation dan therapy), derajat 
menengah atau derajat semu yaitu degrees of tokenism (information, consultation, dan placation), dan terakhir adalah derajat tertinggi yaitu degrees of citizen power (partnership, delegated power, dan citizen control).

\section{Partisipasi Individu Dalam Kegiatan Kelompoktani}

Tingkat partisipasi individu di Kelompoktani Irmas Jaya adalah sebagian besar berada pada tingkat Partnership (bekerjasama) sebanyak 13 orang atau 43,33 persen, Untuk lebih jelasnya mengenai tingkat partisipasi individu dalam kegiatan kelompoktani dapat di lihat pada Tabel 8 berikut ini.

Tabel 8. Tingkat Partisipasi Individu Dalam Kegiatan Kelompoktani

\begin{tabular}{|c|l|c|c|}
\hline No & Tingkat Partisipasi & $\begin{array}{c}\text { Jumlah Petani } \\
\text { (Orang) }\end{array}$ & $\begin{array}{c}\text { Persentase } \\
(\%)\end{array}$ \\
\hline 1. & Consultation & 1 & 3,33 \\
\hline 2. & Placation & 4 & 13,33 \\
\hline 3. & Partnership & 13 & 43,33 \\
\hline 4. & Delegated Power & 10 & 33,33 \\
\hline 5. & Citizen Control & 2 & 6,67 \\
\hline \multicolumn{2}{|c|}{ Jumlah } & $\mathbf{3 0}$ & $\mathbf{1 0 0 , 0 0}$ \\
\hline
\end{tabular}

Berdasarkan tabel diatas maka dapat disimpulkan bahwa tingkat partisipasi individu dalam kegiatan Kelompoktani Irmas Jaya sebagian besar berada pada derajat tertinggi yaitu degrees of citizen power (partnership, delegated power, dan citizen control) sebanyak 25 orang atau 88,33 persen.

\section{Partisipasi Kelompoktani}

Derajat keterlibatan petani/masyarakat diukur dari variabel-variabel tingkat kehadiran dalam pertemuan, keaktifan dalam diskusi, keterlibatan dalam kegiatan fisik dan kesepakatan untuk membayar sumbangan. Dari keempat analisis tersebut, sehingga dapat diperoleh tingkat partisipasi kelompoktani sebagaimana pada Tabel 9 berikut ini.

Tabel 9. Tingkat Partisipasi Kelompoktani

\begin{tabular}{|c|l|c|}
\hline No & \multicolumn{1}{|c|}{ Variabel } & Skor \\
\hline 1 & Tingkat kehadiran dalam pertemuan & 190 \\
\hline 2 & Keaktifan dalam berdiskusi dan menyampaikan pendapat & 193 \\
\hline 3 & Keterlibatan dalam kegiatan fisik & 173 \\
\hline 4 & Kesediaan untuk membayar & 164 \\
\hline \multicolumn{2}{|c|}{ Jumlah } & $\mathbf{7 2 0}$ \\
\hline
\end{tabular}

Berdasarkan Tabel 9 maka tingkat partisipasi Kelompoktani Irmas Jaya termasuk ke dalam tingkat Partnership atau bekerjasama (tangga keenam dari delapan tangga Arsntein), karena memiliki skor 720 .

\section{KESIMPULAN DAN SARAN \\ Kesimpulan}

Berdasarkan hasil penelitian dan pembahasan, maka dapat ditarik kesimpulan sebagai berikut:

1) Karakteristik sosial ekonomi petani peserta kegiatan SL-PTT padi sawah di Kelompoktani Irmas Jaya sebagian besar berada pada kategori sedang sebanyak 25 orang atau 83,33 persen, terbesar kedua berada pada kategori tinggi sebanyak 3 orang atau 10,00 persen dan yang terakhir berada pada kategori rendah sebanyak 2 orang atau 6,67 persen.

2) Tingkat partisipasi petani dalam kegiatan di Kelompoktani Irmas Jaya adalah berada di tangga Partnership atau bekerjasama level Citizen Power yaitu dapat diartikan bahwa petani/masyarakat yang hadir dalam rapat/pertemuan tersebut dapat bernegosiasi dan terlibat dalam pengambilan keputusan. 


\section{Saran}

Berdasarkan kesimpulan yang didapat, maka dapat disarankan beberapa hal diantaranya :

1. Petani diharapkan lebih berpartisipasi lagi dalam melaksanakan suatu kegiatan, karena dengan adanya partisipasi dari petani kegiatan tersebut akan berjalan lebih baik lagi.

2. Pengurus kelompoktani harus lebih mengikutsertakan anggota dalam menetapkan dan mengevaluasi keputusan dan kebijakan.

3. Peran penyuluh pertanian sangat dibutuhkan dalam pembinaan kelompoktani terutama untuk memotivasi, memberikan arahan dan mengawasi agar para petani mampu mengikuti dan mencapai tujuan dari kegiatan.

\section{DAFTAR PUSTAKA}

Daniel, M. 2003. Metode Penelitian Sosial Ekonomi. Bumi Aksara. Jakarta

Dinas Pertanian dan Ketahanan Pangan Kota Banjar. 2013. Petunjuk Teknis Sekolah Lapangan Pengelolaan Tanaman Terpadu (SL_PTT) padi dan Jagung Tahun 2013. Banjar.

Hasyim, H. 2006. Analisis Hubungan Karakteristik Petani Kopi Terhadap Pendapatan (Studi Kasus: Desa Dolok Seribu Kecamatan Paguran Kabupaten Tapanuli Utara). Jurnal Komunikasi Penelitian. Lembaga Penelitian. Universitas Sumatera Utara, Medan.

Iwan. 2010. Analisis Hubungan Karateristik Petani dengan Partisipasi Petani terhadap Program Pengembangan Agribisnis Jagung Hibrida pada Kabupaten Karanganyar. http://iwansas.wordpress.com. Diakses 13 April 2015.

Mar, 2010. SL-PTT. http:/www.IT Koran Sore Wawasan.com. Diakses 29 Maret 2015.

Nurdin. 2000. Pengantar Demografi. Lembaga Demografi FE Universitas Indonesia. Jakarta.
Soleh. 2013. Journal On Social Economic Of Agriculture and Agribusiness Vol 2, No. 9. hal. 4.

Sudjana. 2000. Metode Statistik. Penerbit Tarsito. Bandung. 